\title{
الحماية الاولية للاطفال من مخاطر النزاعات المسلحة
}

\author{
Doi: $10.23918 /$ ilic2020.20

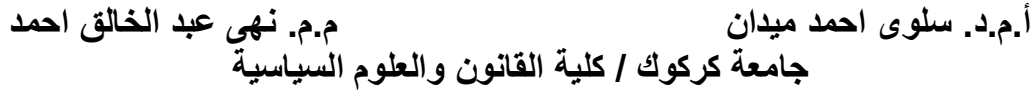 \\ المقدمة
}

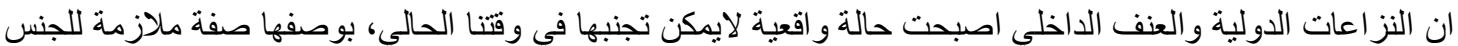

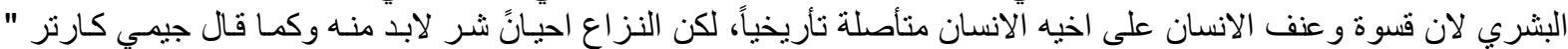

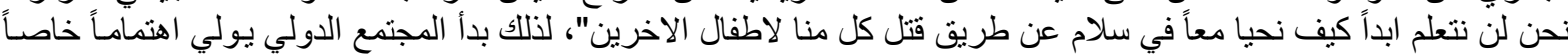

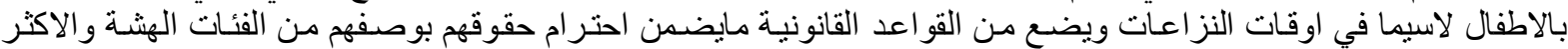
حاجة لمثل هذه الرعاية و الحماية.

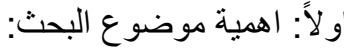

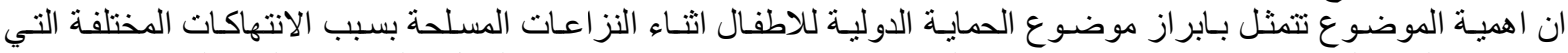

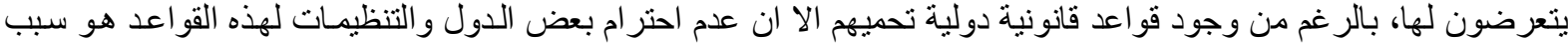

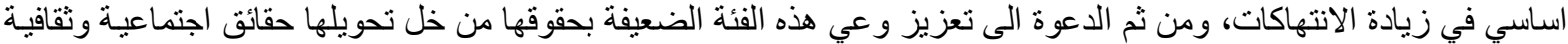

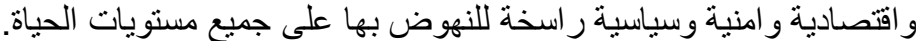
ثانياً: اشكالية موضو ع الشية البحث:

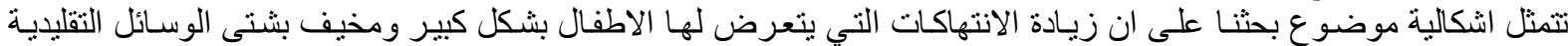

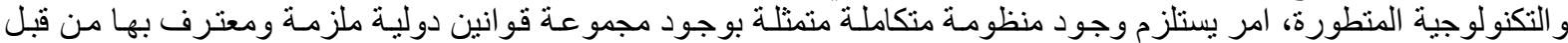

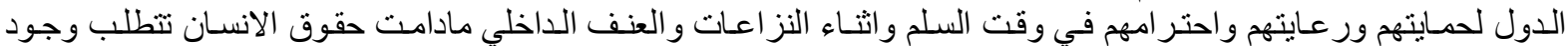
مجمو عة تشريعات دولية مترابطة ومتكاملة معترف وائه بها من المجتمع الدولي.

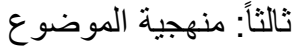

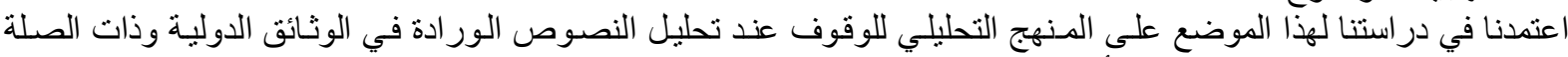

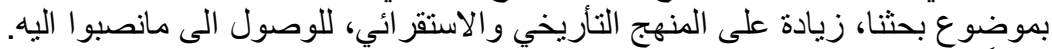
رابعاً: هيكلية البحث:

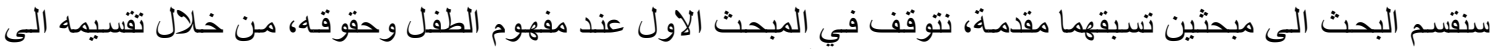

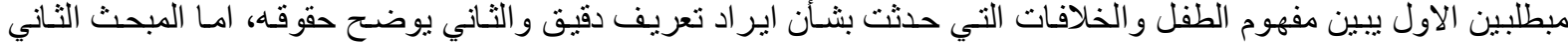
سيوضح انتهاكات حقوق الطفل والحماية المقررة لهم الثناء النزاعات المسلحة، من خلال تقسيمه الى مطلبين كذللك و اختتمنا البحث و الله الموفق خلان بخاتمة تضمنت اهم الاستنتاجات و المقترحات واتهات

\section{المبحث الاول \\ مفهوم الطقل وحقوقه الاوله}

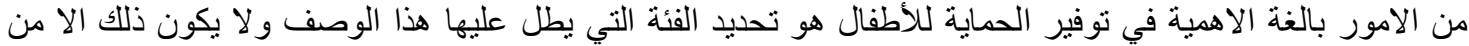

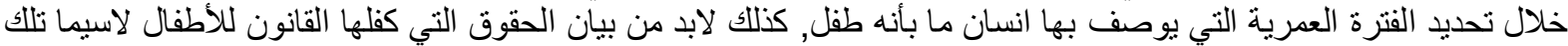

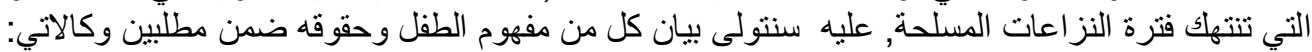
المطلب الاول التعريف بالطفل

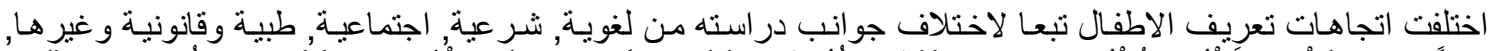

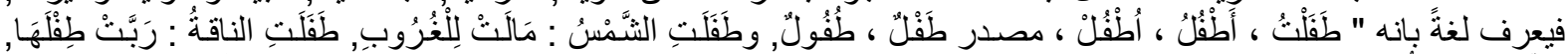

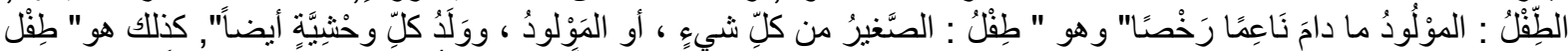

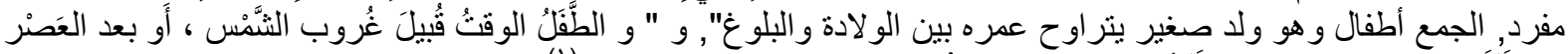

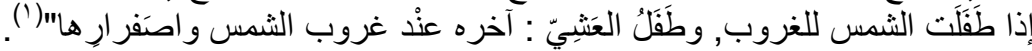

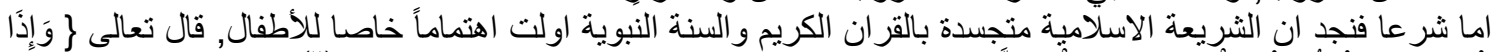

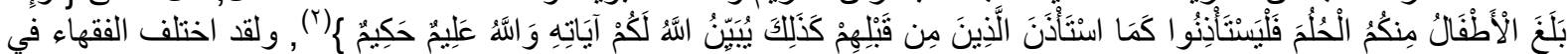

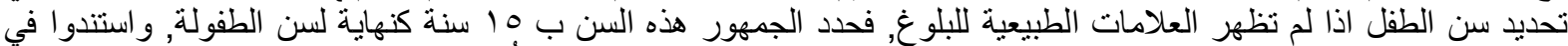

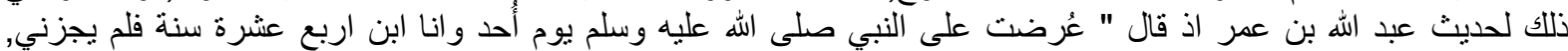

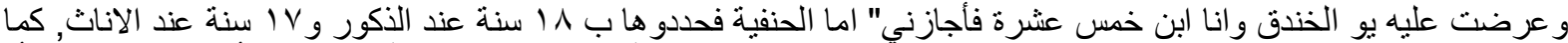

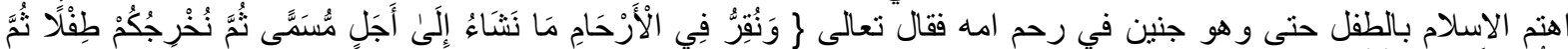

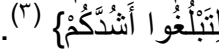

(') ـ قاموس المعجم الوسيط ،اللغة العربية المعاصر ،الرائد ،لسان العرب ،القاموس المحيط. قاموس عربي عربي, متوفر على الموقع الالكتروني,

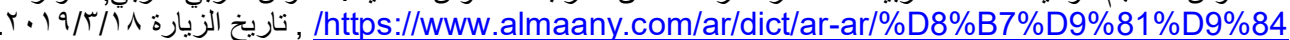

09
09 
كذلك اهتم العلماء بدراسة الطفل وتعريفه من عدة جوانب نفسية واجتماعية وطبية, فعرفه علماء النفس بانه " الإنسان

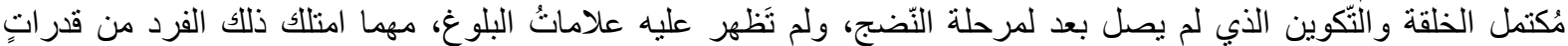

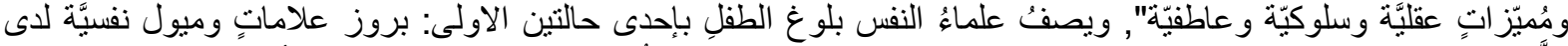

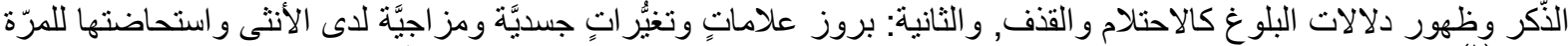

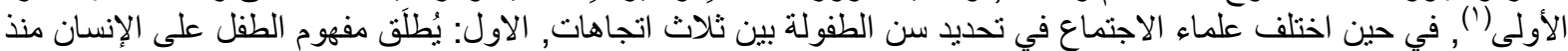

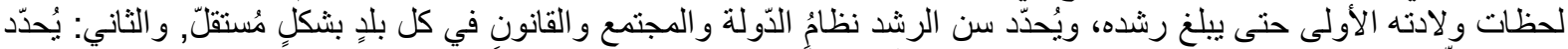

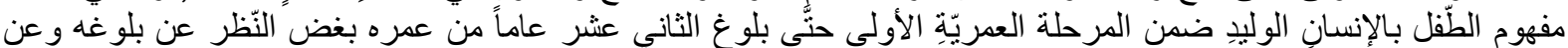

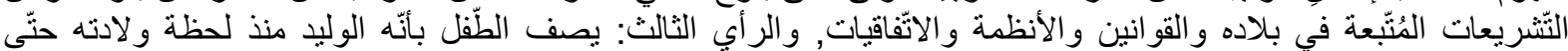

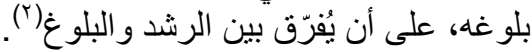

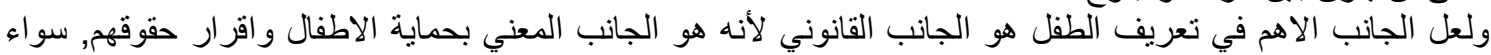

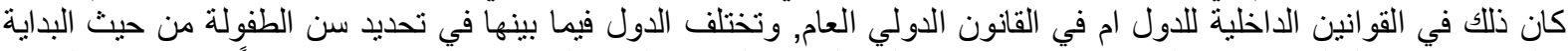

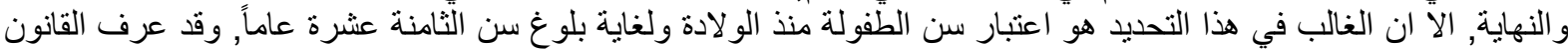

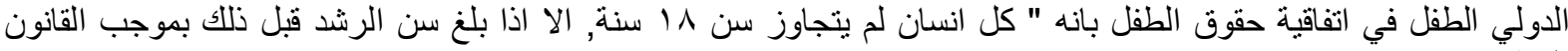

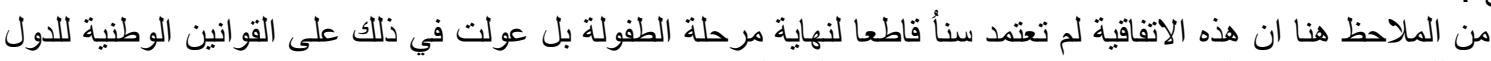

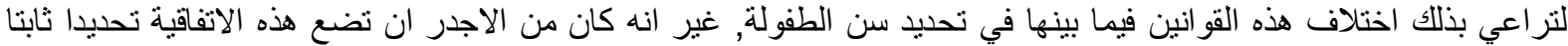

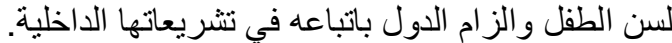

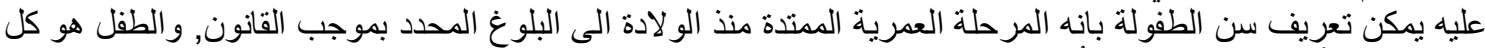
انسان منذ ولادته حياً ولغاية بلو غه قانوناً.

\section{المطلب الثاني \\ حقوق الطقل}

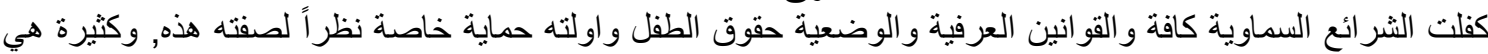

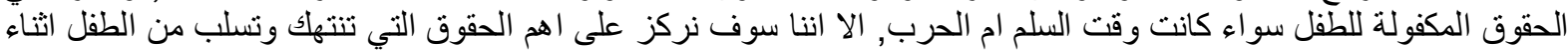

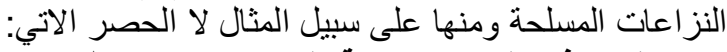

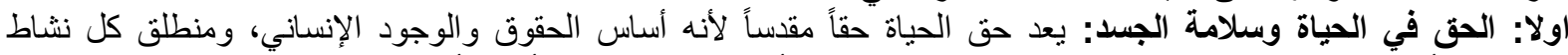

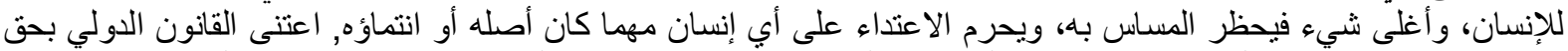

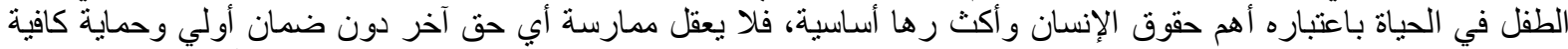

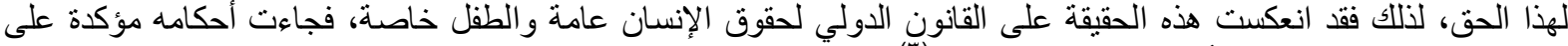

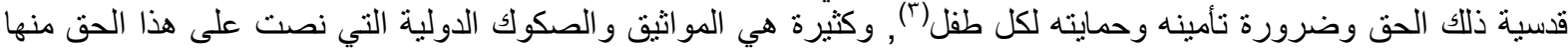

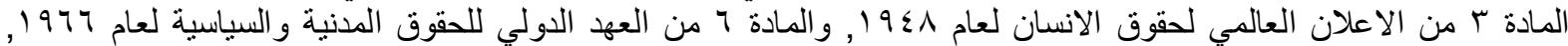

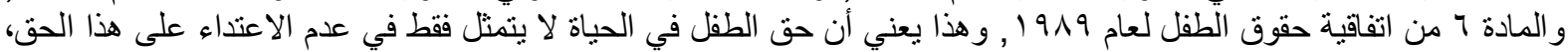

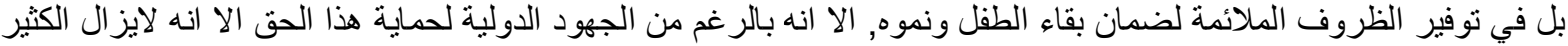

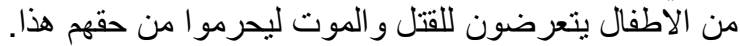

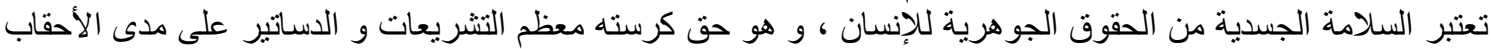

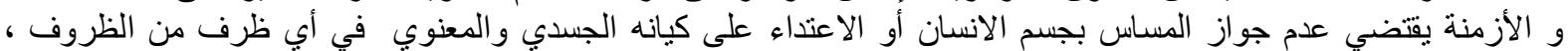

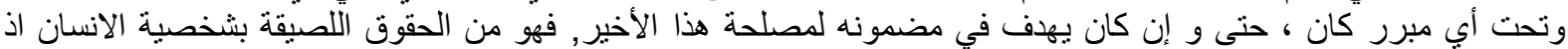

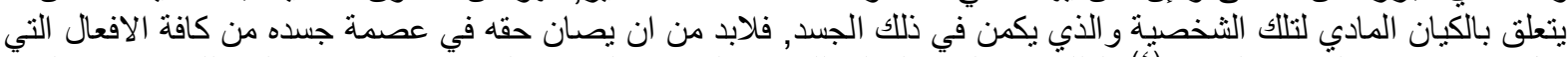

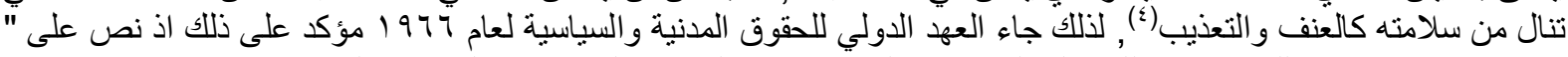

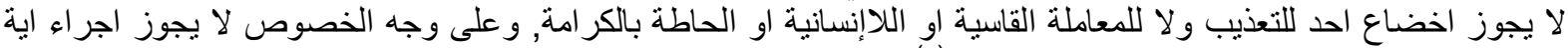

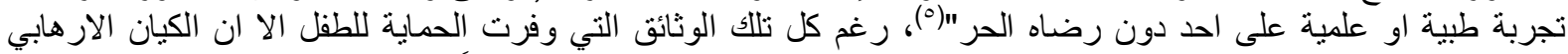

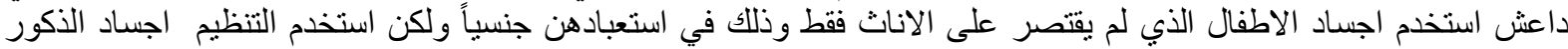

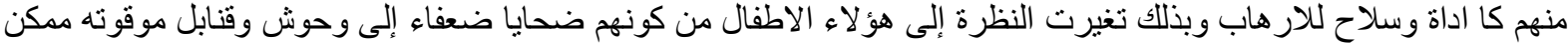

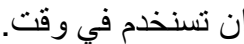

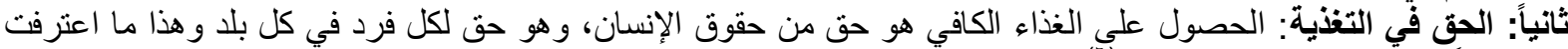

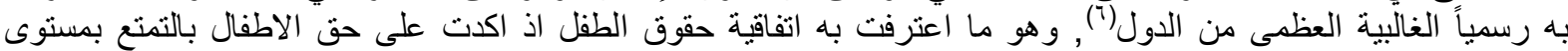

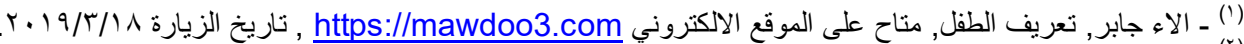

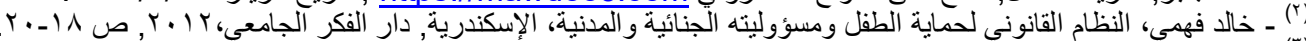

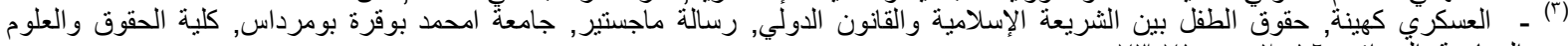

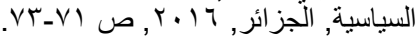

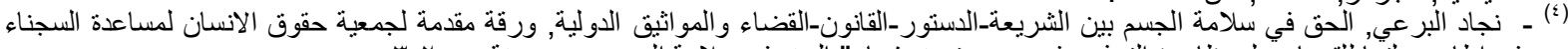

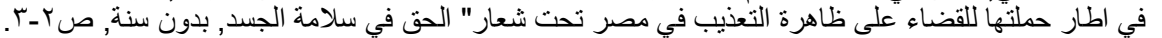

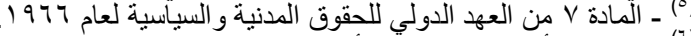

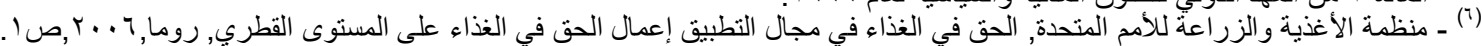




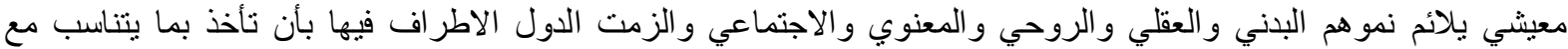

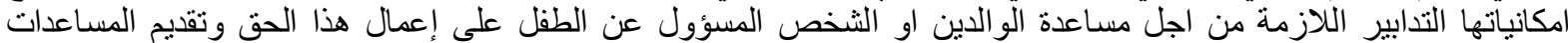

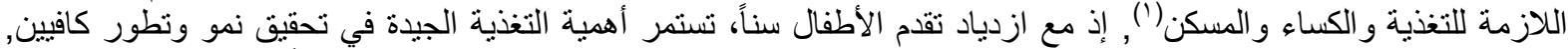

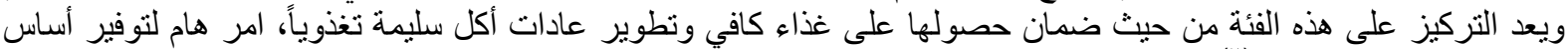

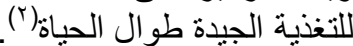

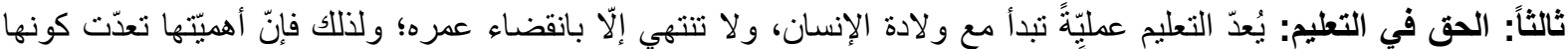

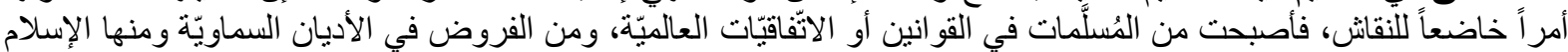

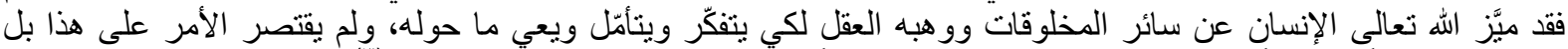

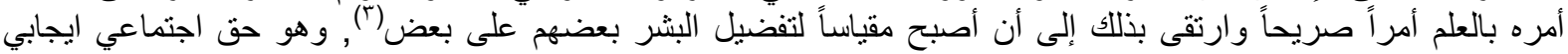

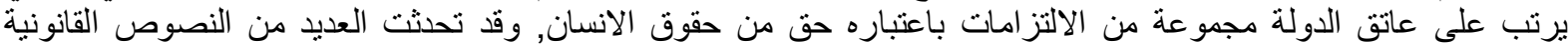

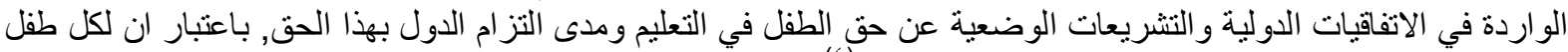

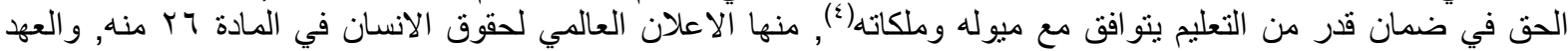

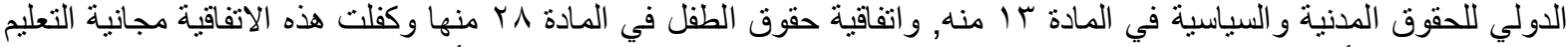

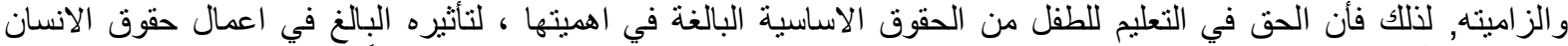

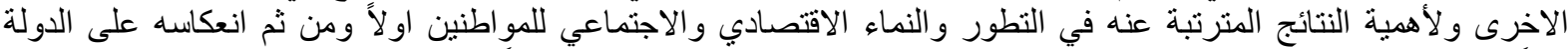

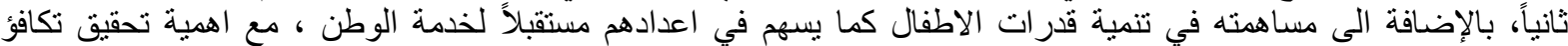

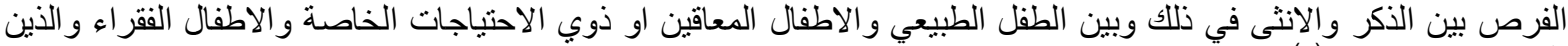

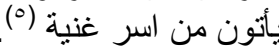
رابعاً: الحق في الرعاية الصحية: يعد الحق في الصحة حق من حقوق الانسان المكفولة للجميع مكرس في الاعلان العالئ العالمي

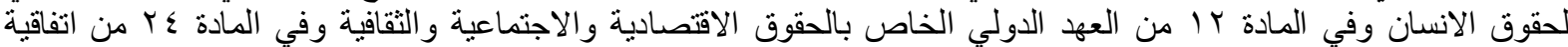

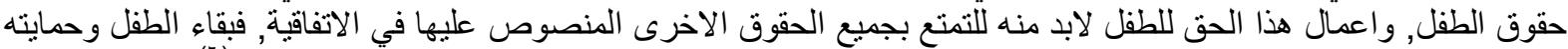

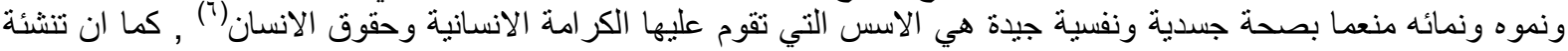

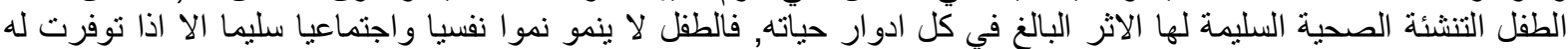

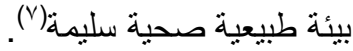

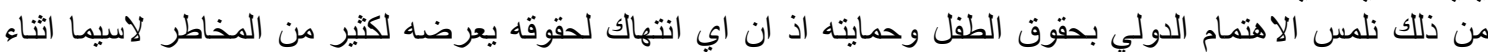

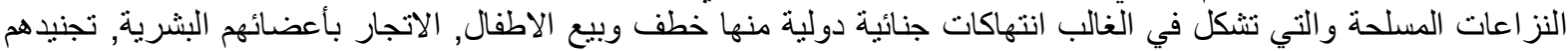

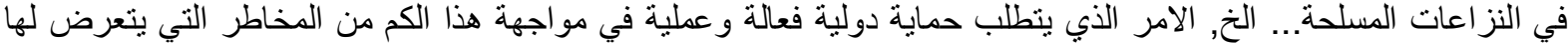
الاطفال, وهذا ما سنتولى بيانه في المبحث الثناني.

\section{المبحث الثاني

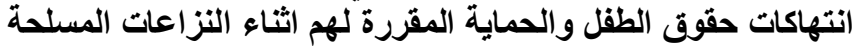

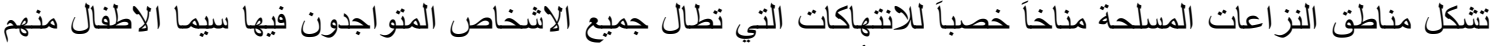

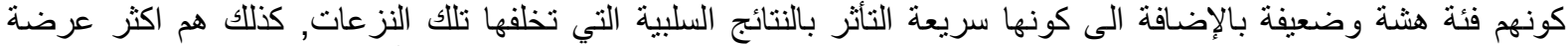

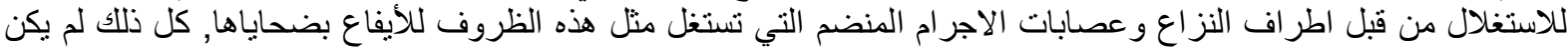

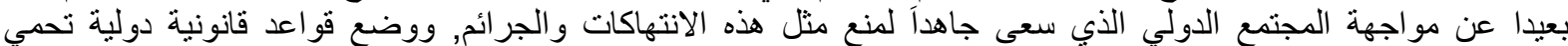

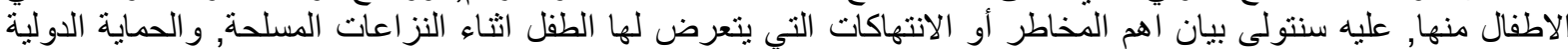

المطلب الاول التي كفلها القانون الدولي له, وكالاتيه:

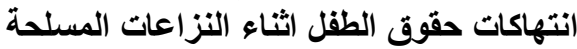

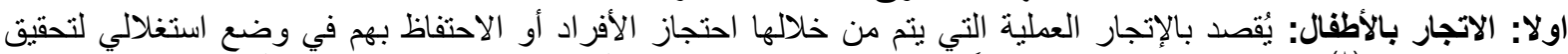

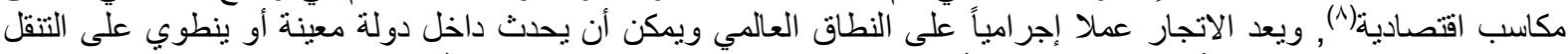

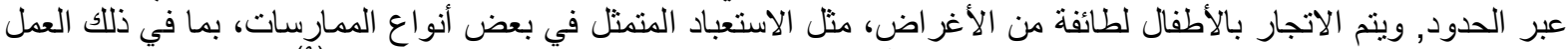

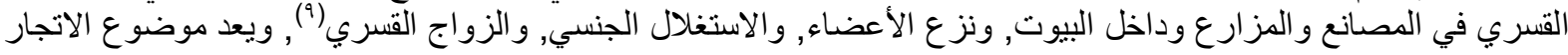
(1) ـ سنان طالب عبد الثهيد, مشكلة حق الطفل في التنمية والحق في التغذية بين الثريعة والقانون, بحث منشور في مجلة مركز دراسات الكوفة, جامعة

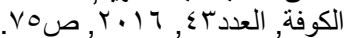

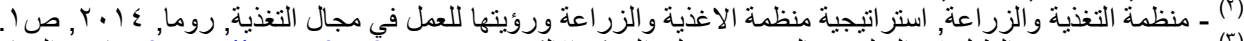

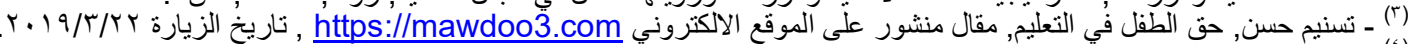

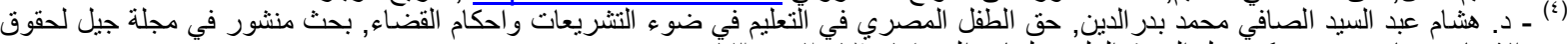

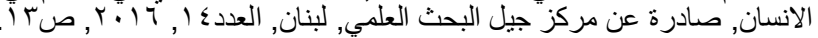

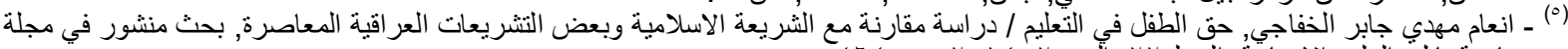

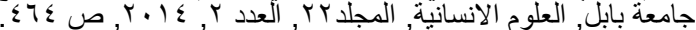

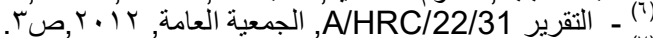

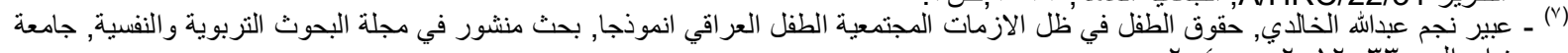

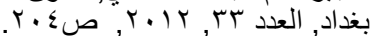

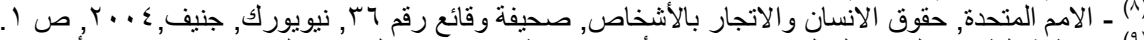

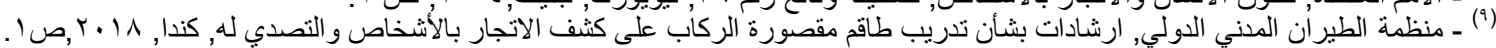




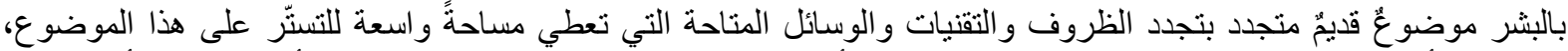

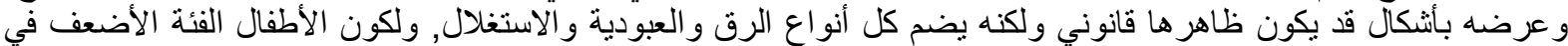

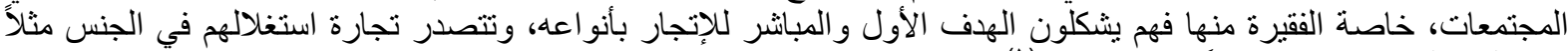

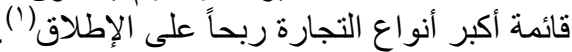

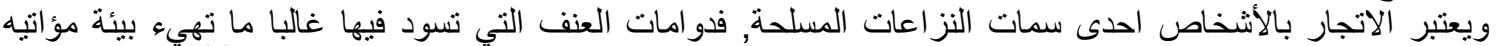

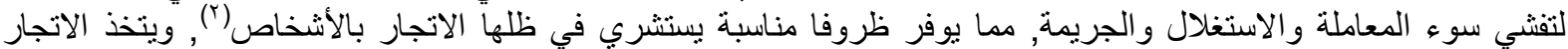

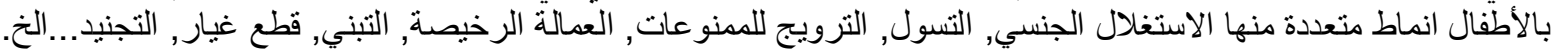

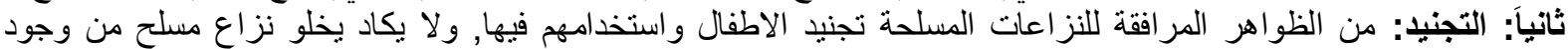

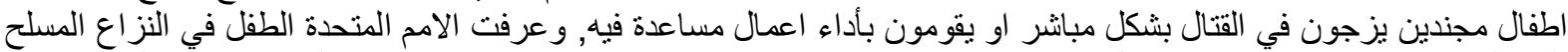

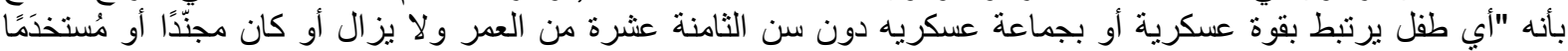

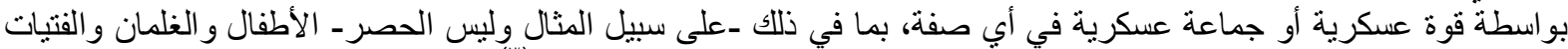

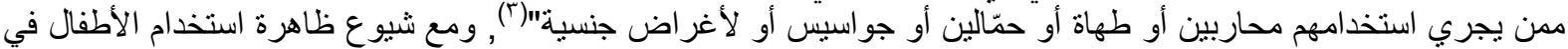

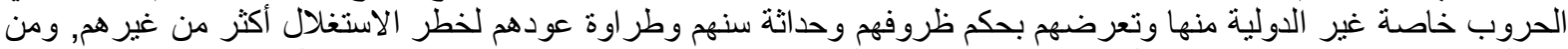

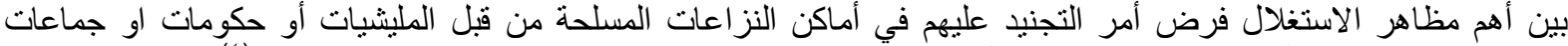

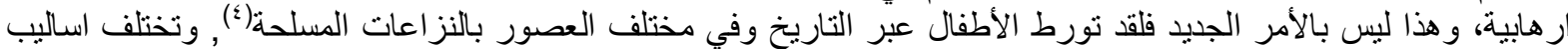

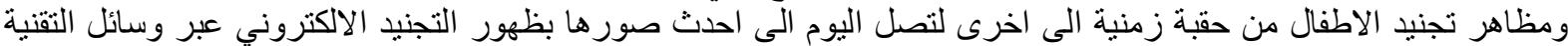

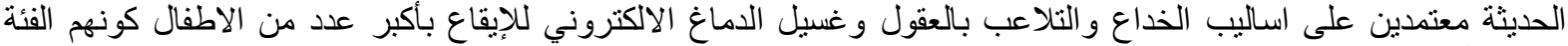

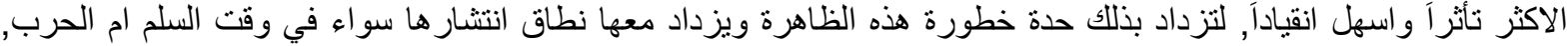

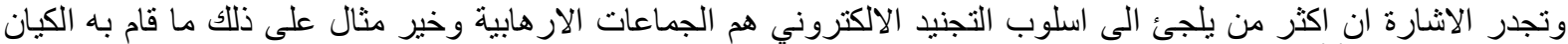

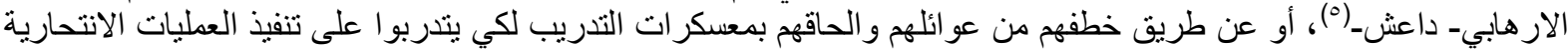

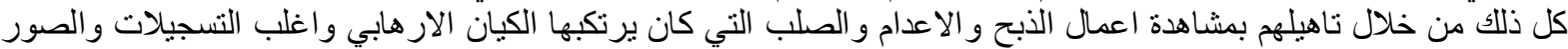

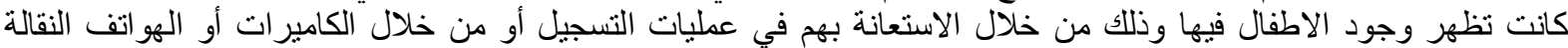

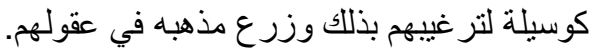

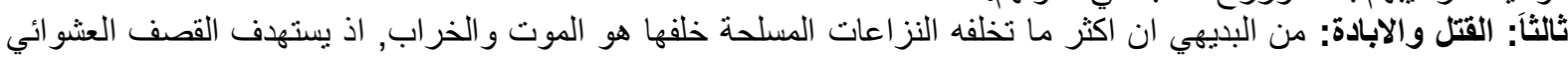

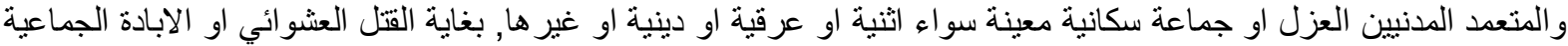

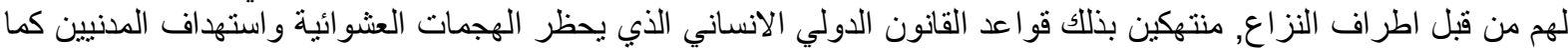

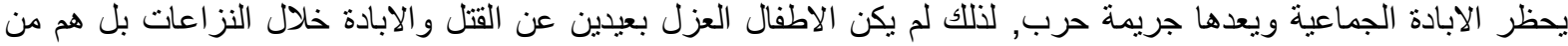

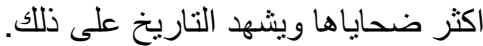

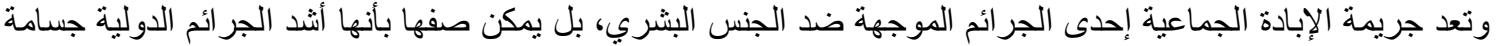

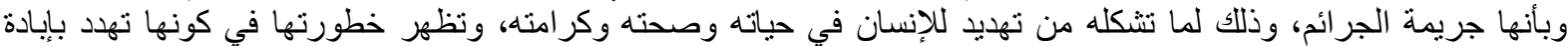

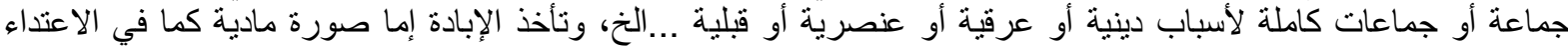

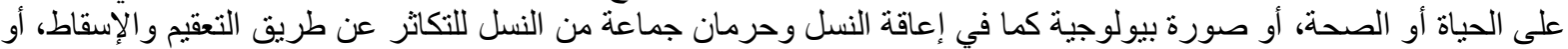

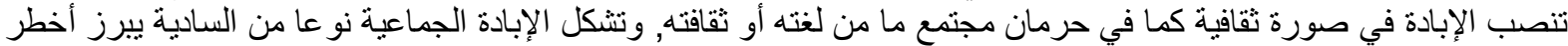

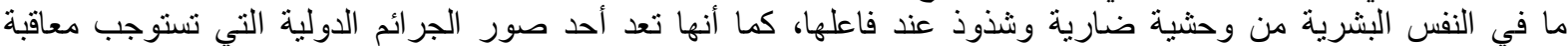

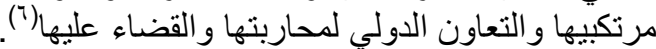

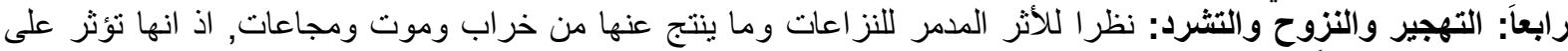

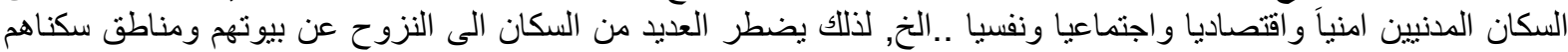

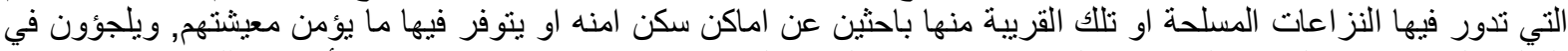

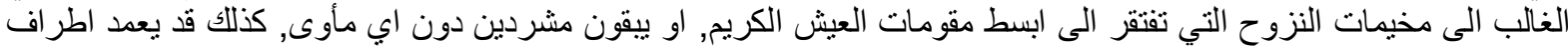

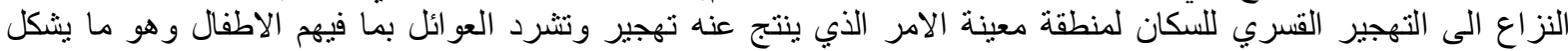

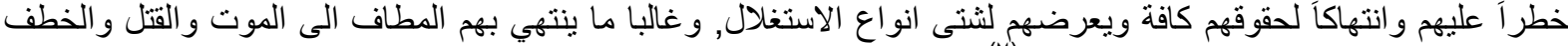

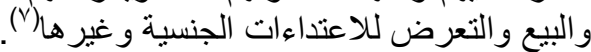

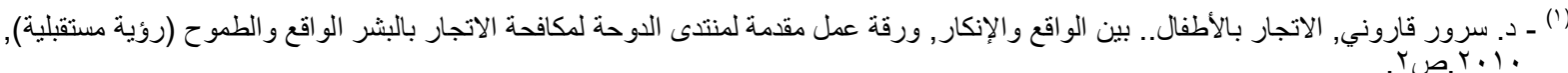

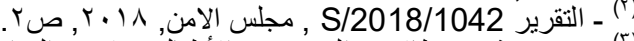

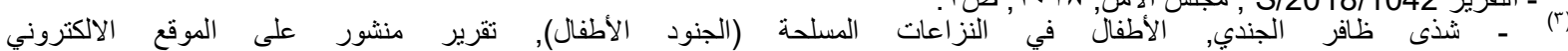
(1)

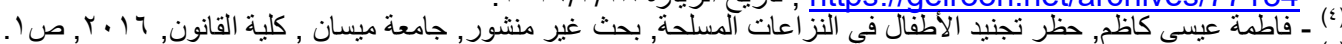

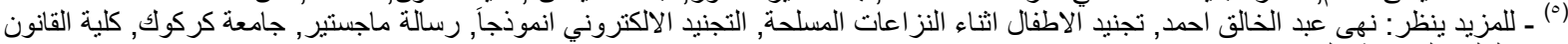

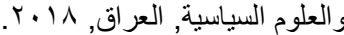

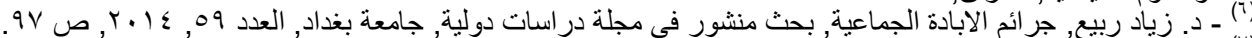

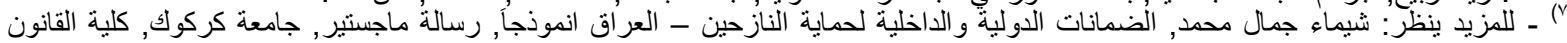

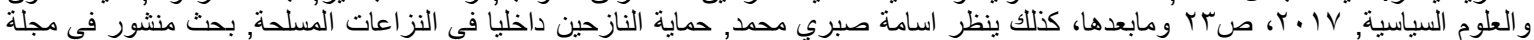

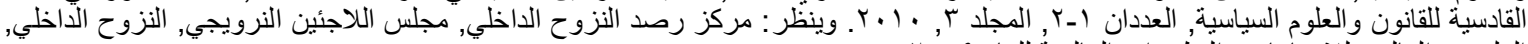

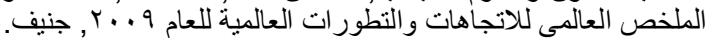


ولا تقتصر وحشية النزاعات المسلحة وما يرتكبه اطر افها من انتهاكات على ما سلف ذكره بل هو غيض من من فيض, وهي وهو

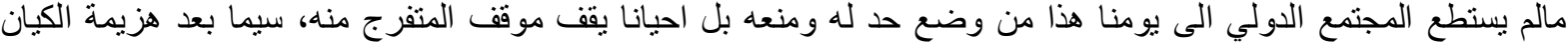

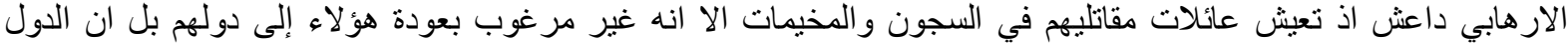

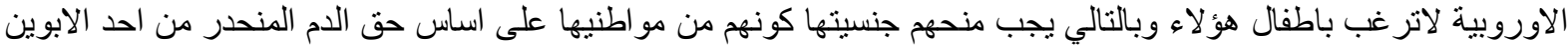

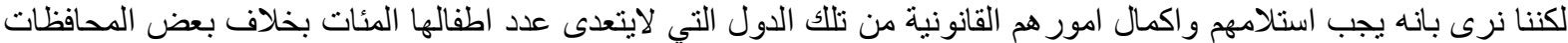

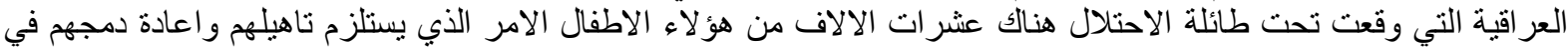

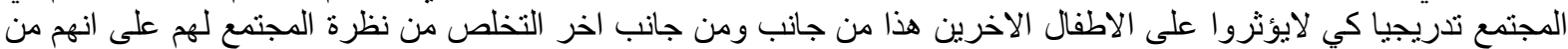

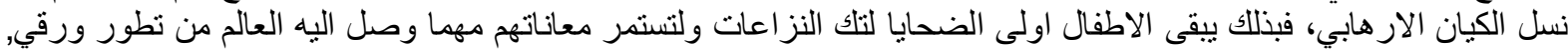

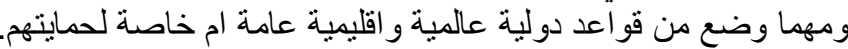
المطلب الثاني

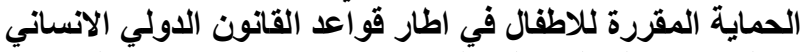

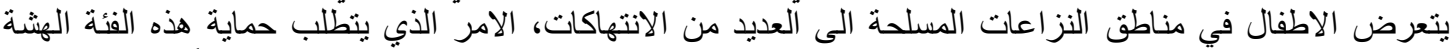

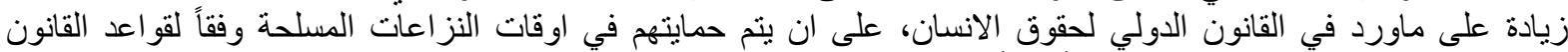

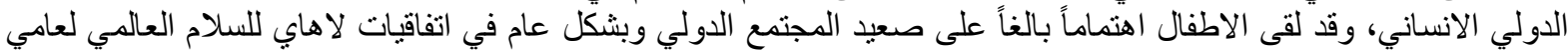

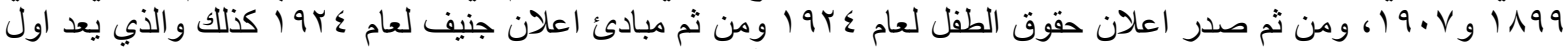

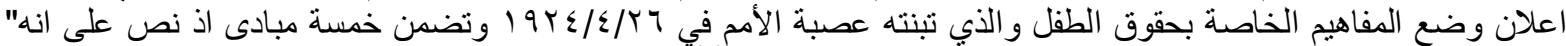

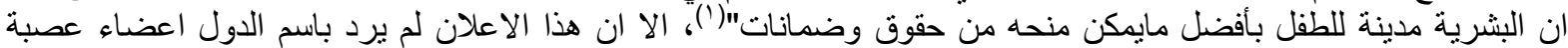

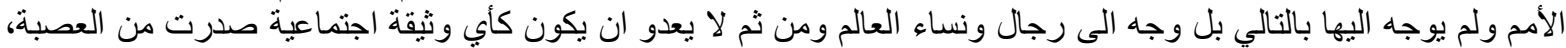

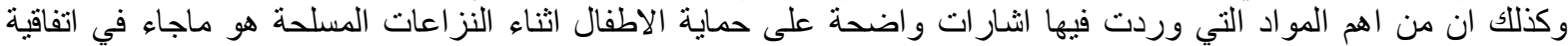

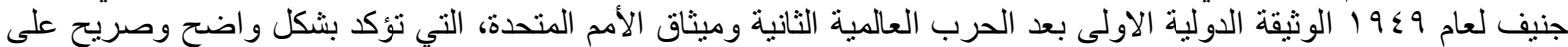

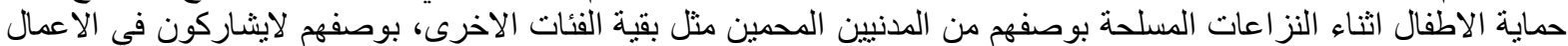

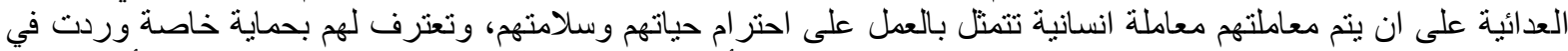

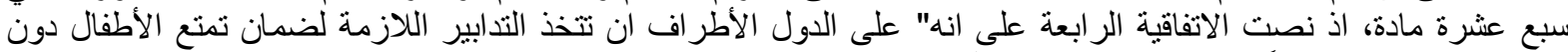

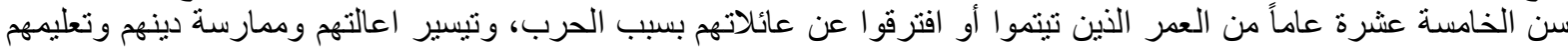

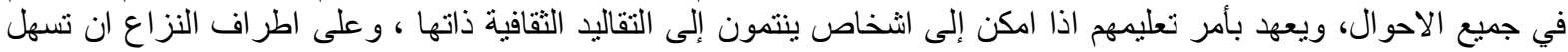

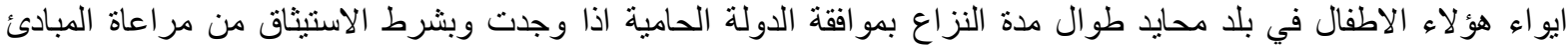

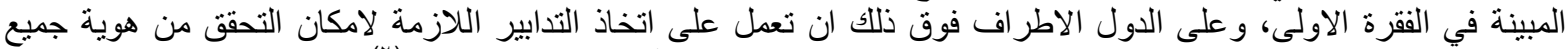

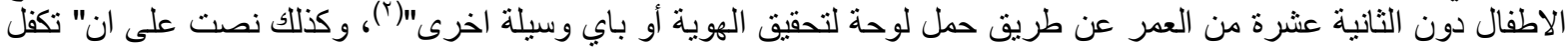

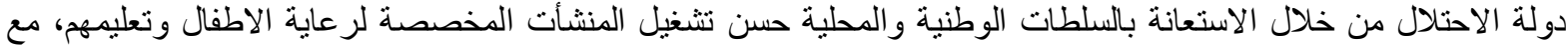

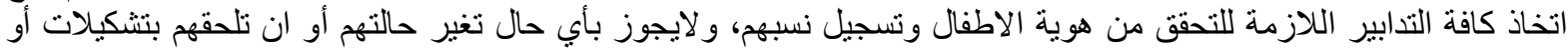

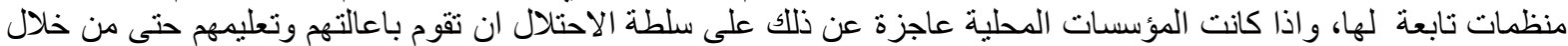

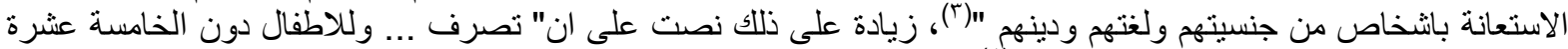

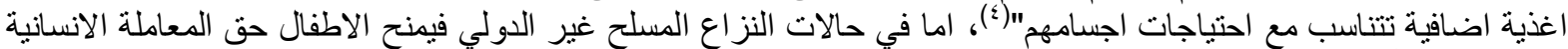

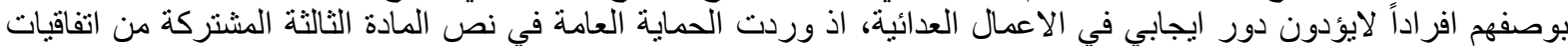

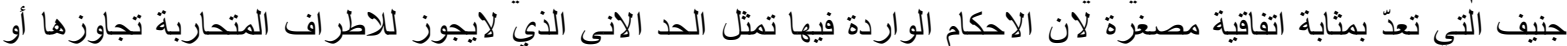

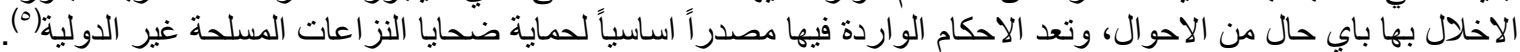

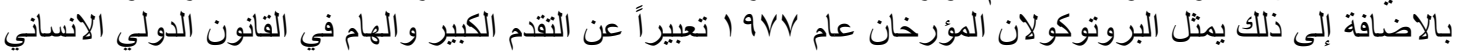

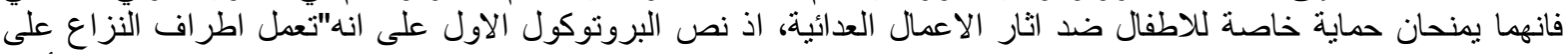

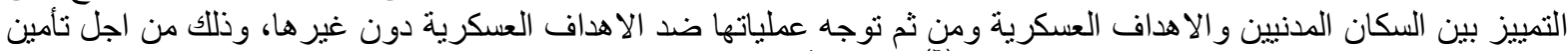

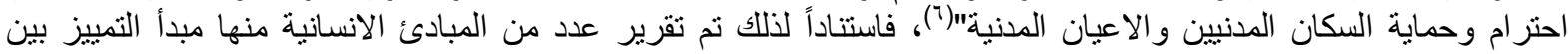

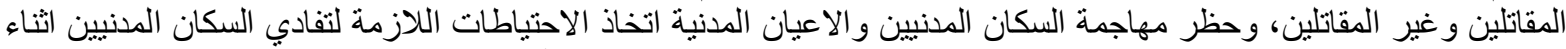

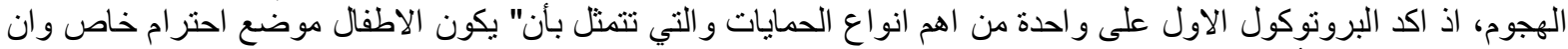

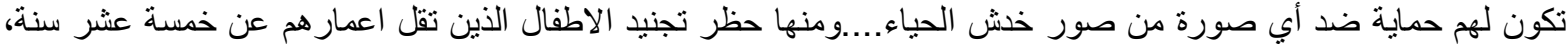

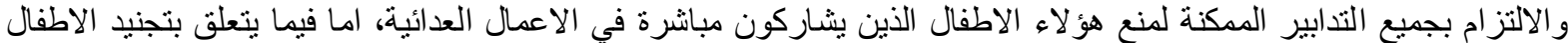

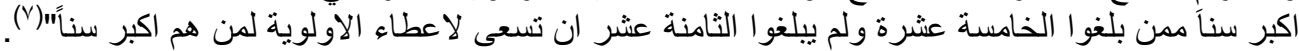

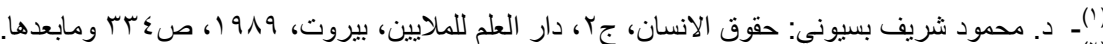

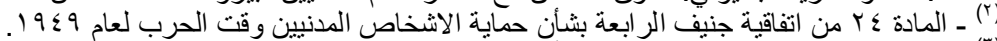

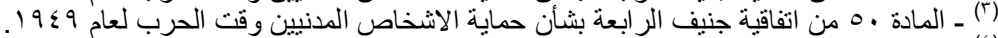

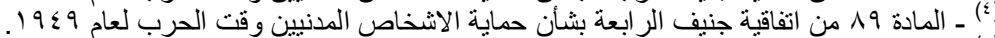

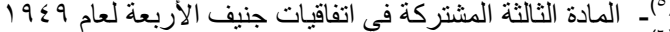

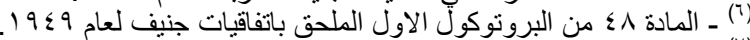

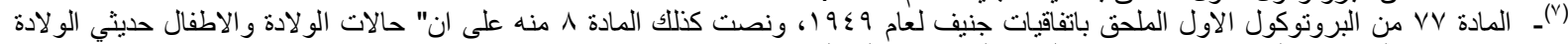

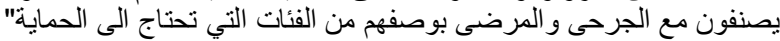




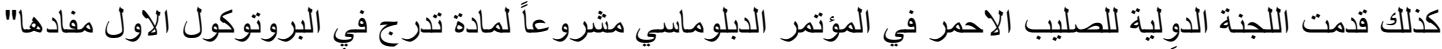

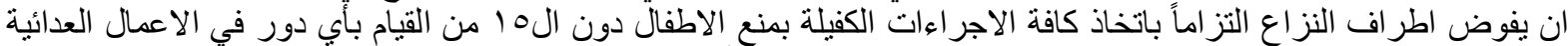

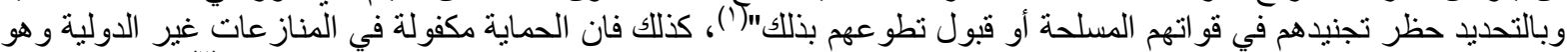

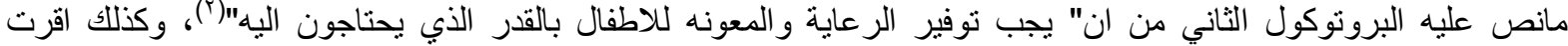

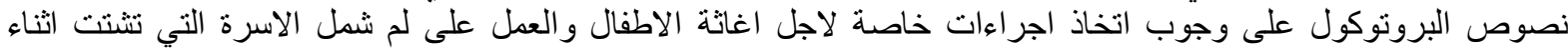

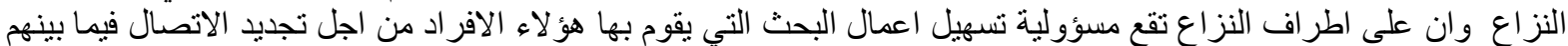

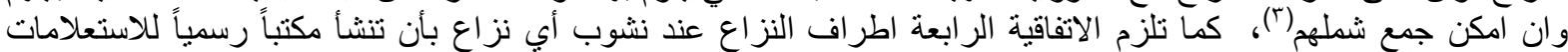

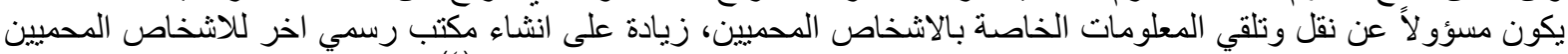

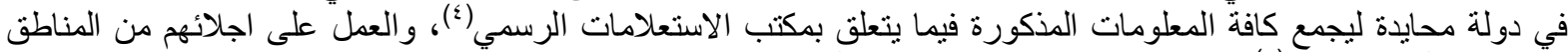

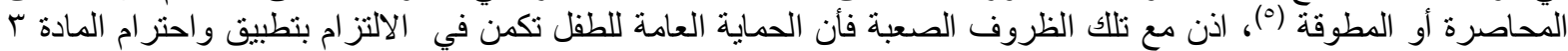

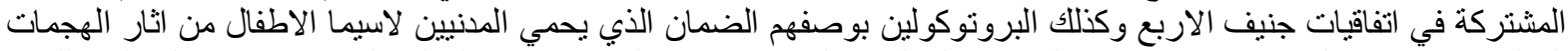

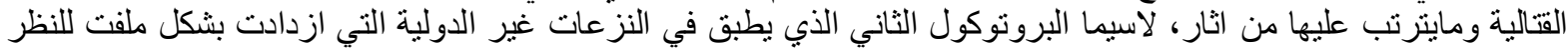

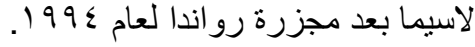

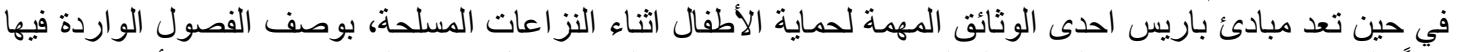

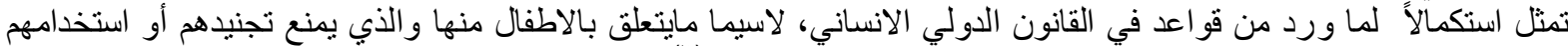

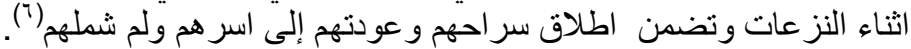

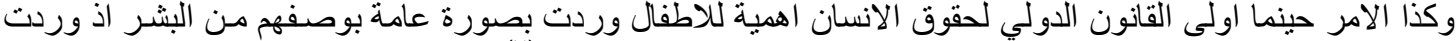

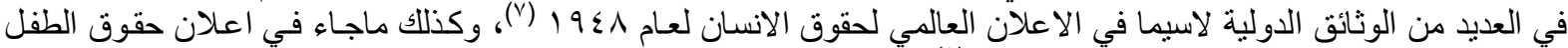

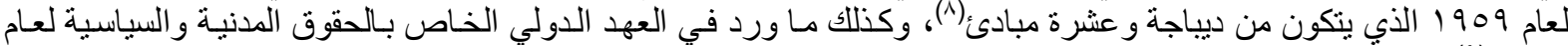

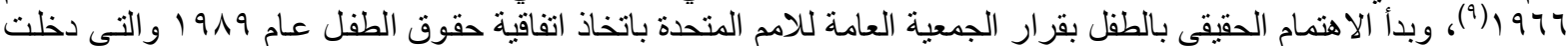

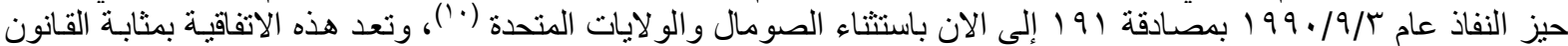

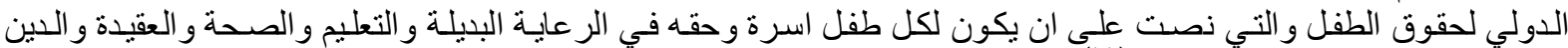

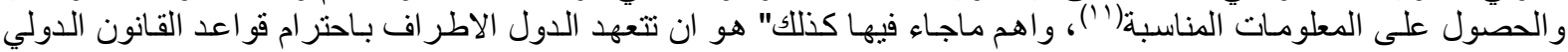

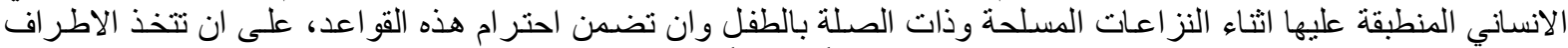

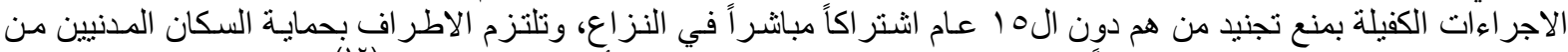

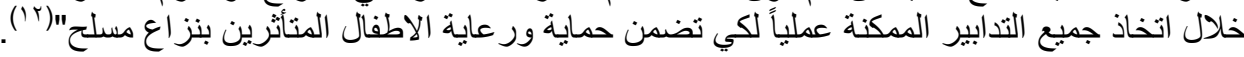

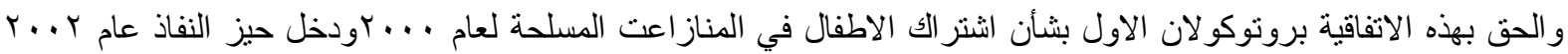

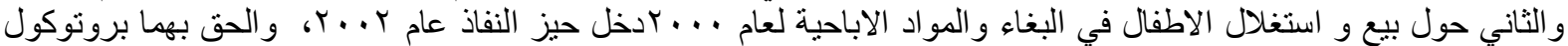

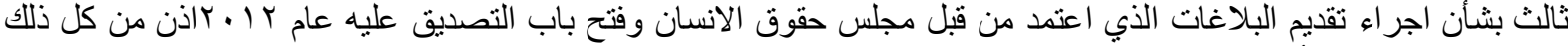

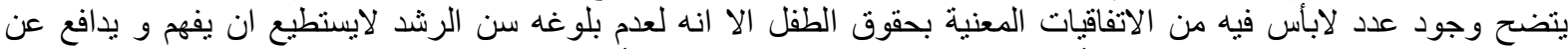

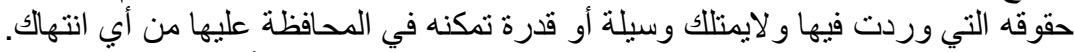
الخاتمة بعد انهينا بحثنا توصلنا في النهاية الى العديد من الاستتناجات و المقترحات نوردها بالاتي: اولاً:الاستتناجات

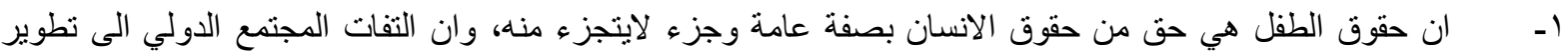
حقوق الانسان هو الذي ادى الى الاهنمام بحقوق هذه الفئة كذلك.

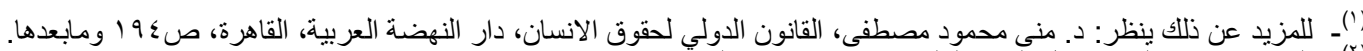
(r)

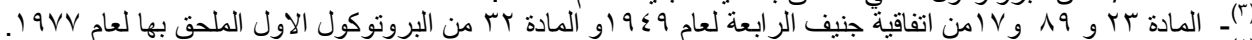

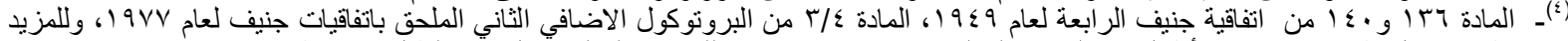

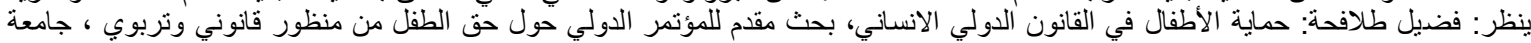

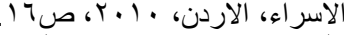

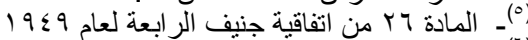

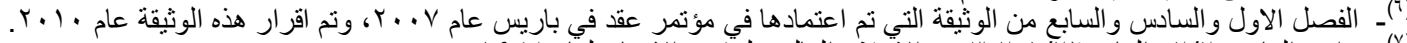

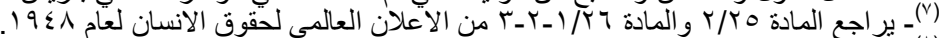

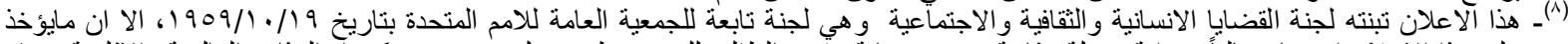

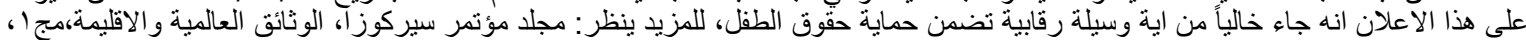

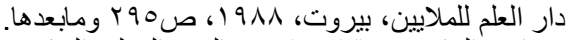

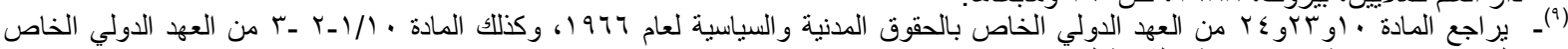

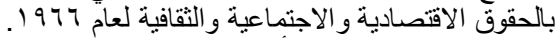

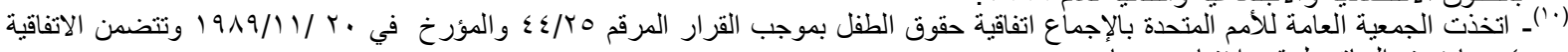

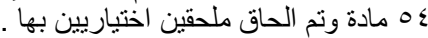

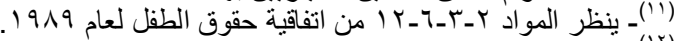
(r) 


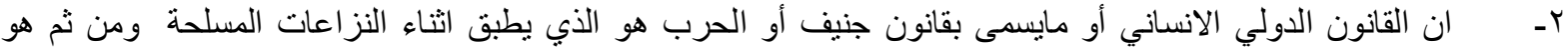

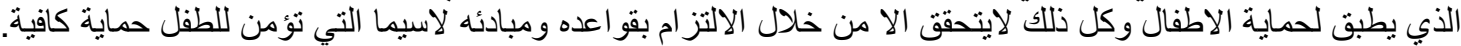

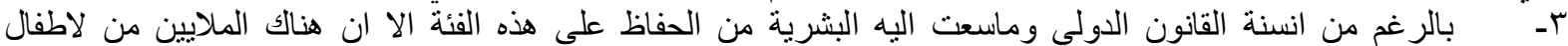

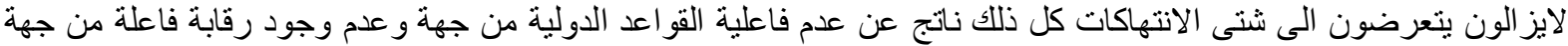

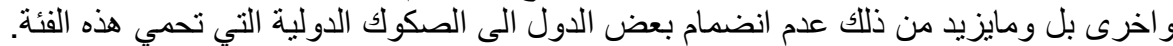

ثانياً: المقترحات

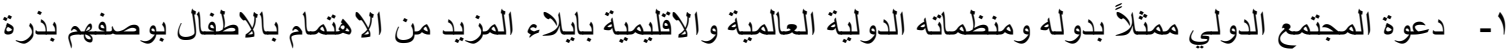

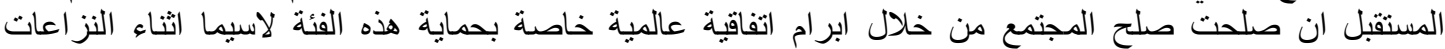
المسلحة و العنف الداخلي.

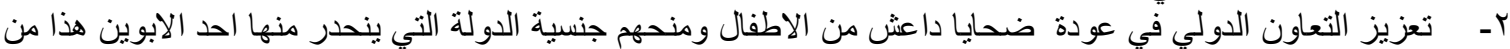

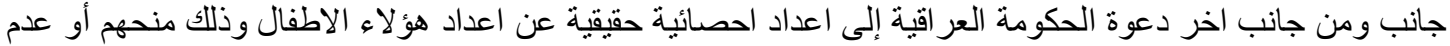

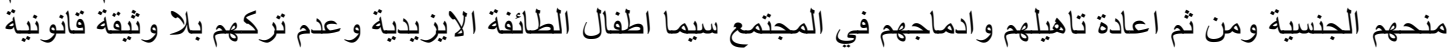

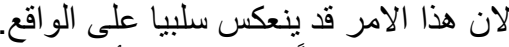

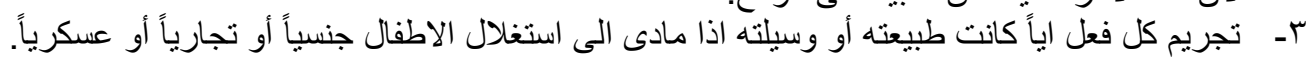

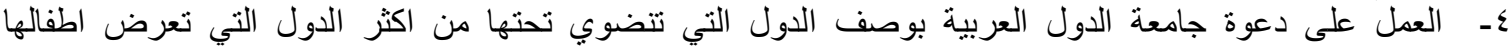

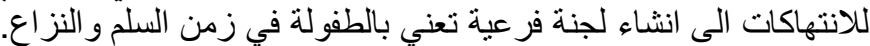

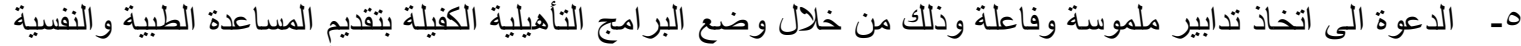

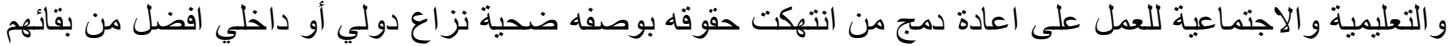

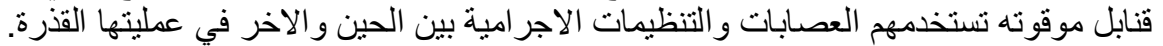

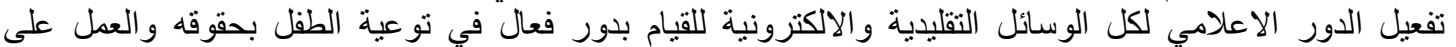

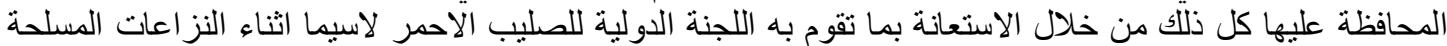

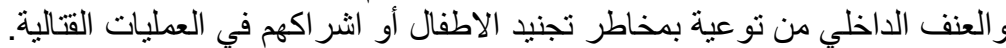

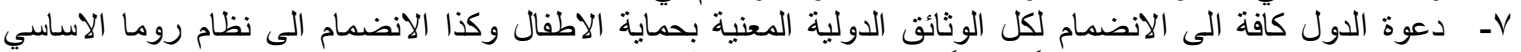

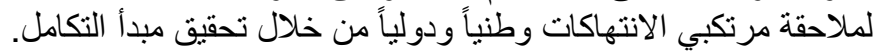
قائمة المصادر والمراجع

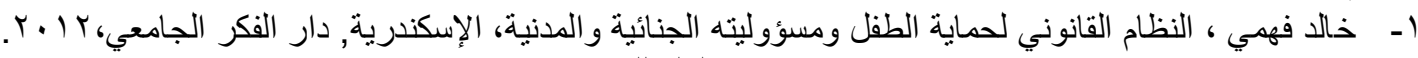

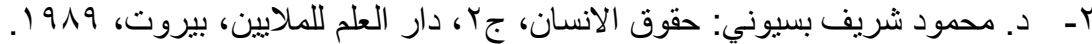

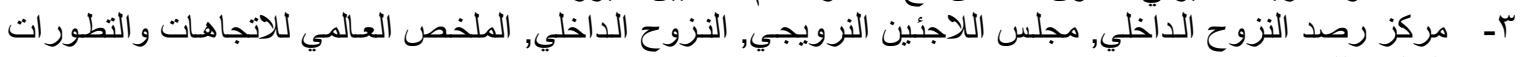

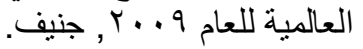
ـ - منظمة الطير ان المدني الدولي, ارشادات بثأن تدريب طاقم مقصورة الركاب على كثف الاتجار بالأشخاص و التصدي

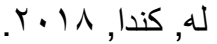

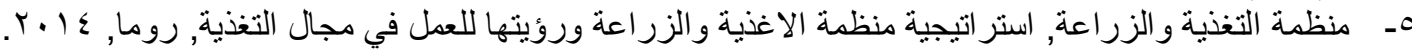

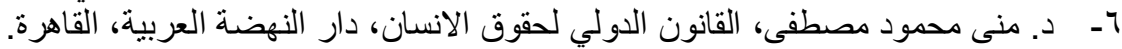
ثانياً:الرسائل و الاطاريح الجامعية

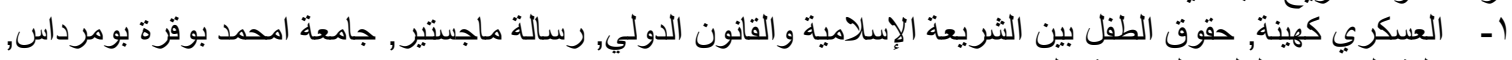

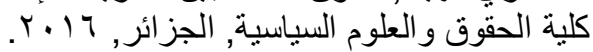

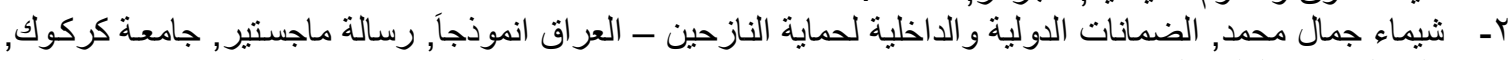

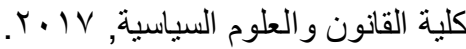

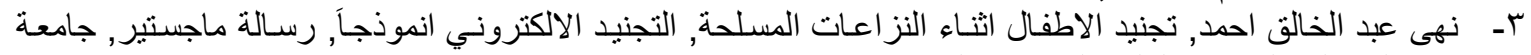

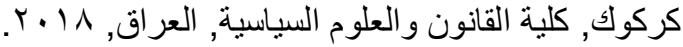
ثالثاً: البحوث و الدوريات

ا - اسامة صبري محمد, حماية النازحين داخليا في النزاعات المسلحة, بحث منشور في مجلة القادية للقانون و العلوم

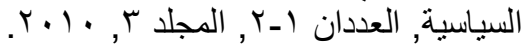

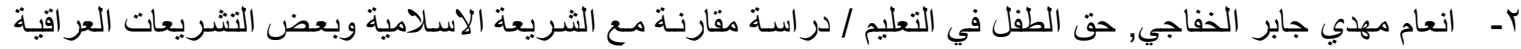

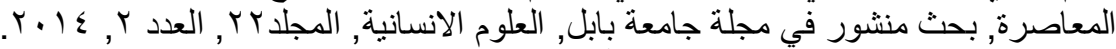

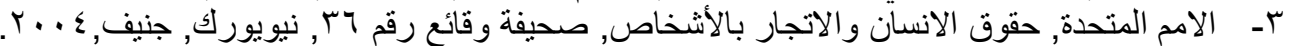

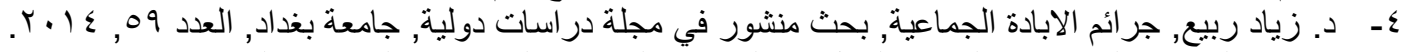

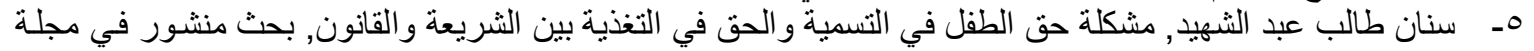

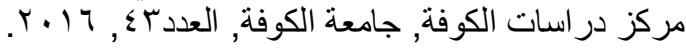


1- عبير نجم عبداله الخالدي, حقوق الطفل في ظل الازمـات المجتمعيـة الطفل العر اقي انموذجا, بحث منشور في مجلة

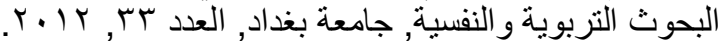

V- فاطمة عيسى كاظم, حظر تجنيد الأطفال في النزاعات المسلحة, بحث غير منشور, جامعة ميسان , كلية القانون,

1- فضيل طلافحة: حماية الأطفال في القانون الدولي الانسـي، بحث مقدم للمؤتمر الدولي حول حق الطفل من منظور

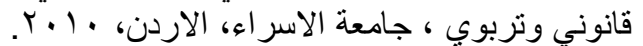

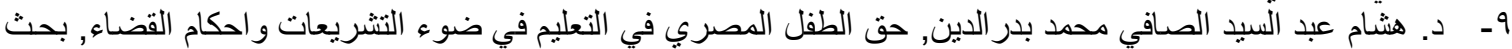

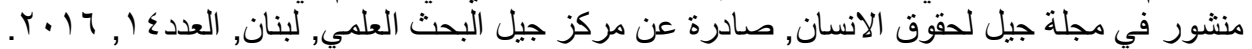
ر ابعاً: الندور ات و والورش فئش

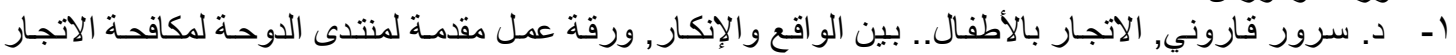

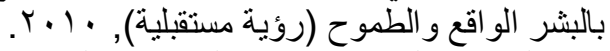

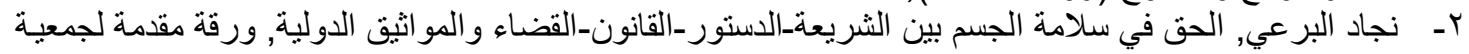

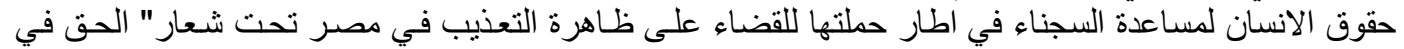

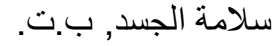
خامساً: الوثائق الدولية التية

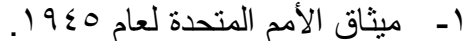

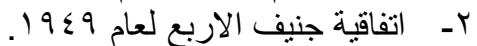

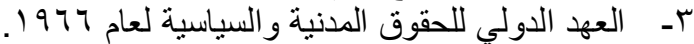

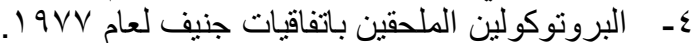

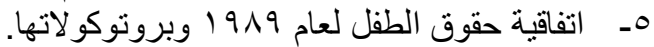

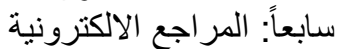

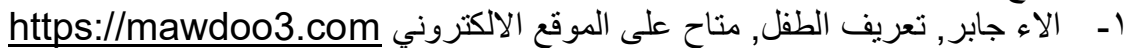

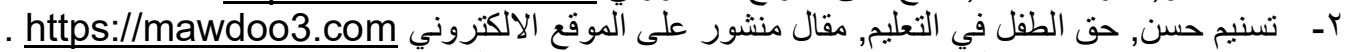

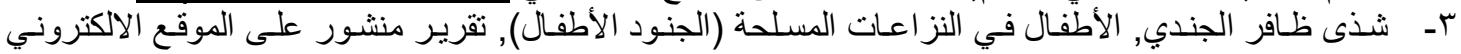
. https://geiroon.net/archives/77184

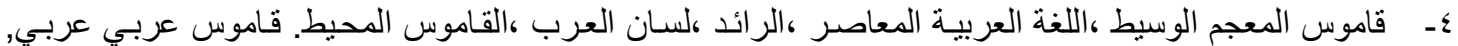

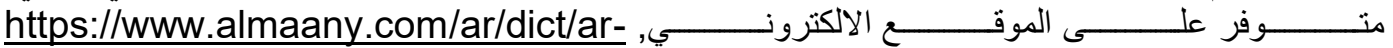

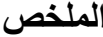

. lar/\%D8\%B7\%D9\%81\%D9\%84

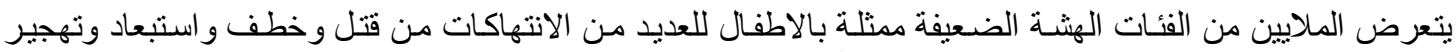

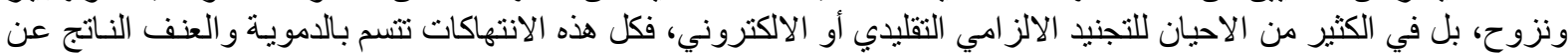

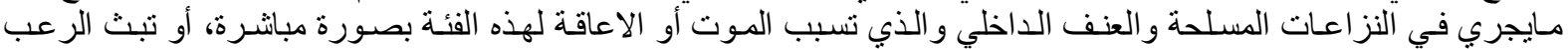

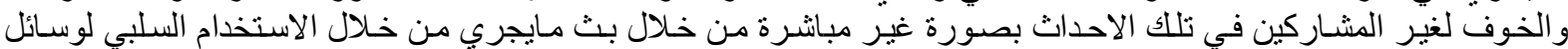

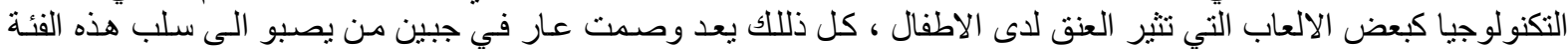

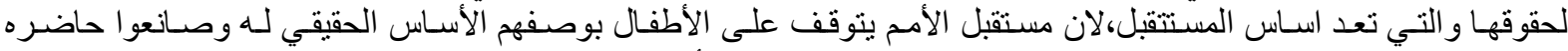

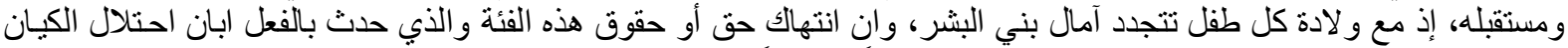
الار هابي داعش لبعض الدول و عذ انتهاكه لحقوقهم انتهاكاً صارخاً للبشرية جمعاء، منطلقين من مبادئ الامح المتحدة.

\section{Summary}

Millions of vulnerable vulnerable groups represented by children are subjected to many violations, including killing, kidnapping, exclusion, displacement and displacement, and in many cases, for conventional or electronic conscription, all of these violations are characterized by bloody and violence resulting from what is going on in armed conflicts and internal violence which causes death or disability to this group Directly, or transmitting terror and fear to those who are not involved in these events indirectly through the transmission of what is happening through the negative use of technology such as some games that raise the neck in children, All this is considered a shame and silence in the forehead of those who aspire to deprive this group of their rights, which is the basis of the future, because the future of nations depends on children as the real basis for it and they make their present and future, as with the birth of every child, the hopes of human beings are renewed, and the violation of the right or rights of these The class is a flagrant violation of all humanity, based on the principles of the United Nations.

Keywords: children, violence, armed conflicts, United Nations. 